Article

\title{
Air Quality Context Information Model for Ubiquitous Public Access to Geographic Information
}

\author{
Sungchul Hong
}

Department of Future Technology and Convergence Research, Korea Institute of Civil Engineering and Building Technology, 283 Goyangdae-ro, Ilsanseo-gu, Goyang-si, Gyeonggi-do 10223, Republic of Korea; shong@kict.re.kr; Tel.: +82-031-995-0874

Received: 21 June 2018; Accepted: 30 July 2018; Published: 4 August 2018

check for updates

\begin{abstract}
The advance in Information Communication Technology (ICT) has contributed to global challenges of improving urban air quality. Ubiquitous computing technology enables citizens to easily access air quality information services without spatial or temporal limitations. Citizens are also encouraged to participate in air quality assessment and environmental governance. These societal and technical changes require a new paradigm to develop an air quality information system and its services. An air quality information system needs to integrate varied types of air quality information from heterogeneous data sources as well as allow citizens to express their concerns about air quality. Thus, a standardized manner is necessary to develop an air quality information system. In this regard, an air quality context information model was designed according to the Ubiquitous Public Access (UPA) context information model defined in the International Organization for Standard (ISO) 19154. For validation and verification purposes, the air quality context information model was implemented in a geographic information system (GIS)-based air quality information system. Implementation results showed that spatially relevant air quality information services were generated from the system, depending on the location and air quality situations near a specific user. Also, citizens can contribute air quality information at their current regions.
\end{abstract}

Keywords: Air Quality Information; Ubiquitous Computing; Pubic Access; Geographic Information System; ISO 19154

\section{Introduction}

Rapid urbanization and industrialization have led to severe deterioration in the atmospheric environments of major cities [1,2]. The World Health Organization (WHO) reported that $92 \%$ of the world's population is exposed to air pollutants beyond the WHO limit [3]. Air pollutants, which include both naturally occurring and anthropogenic substances, are associated with illness and mortality in humans, and with damage to natural and built environments [4]. However, despite the dedicated actions over the past decades of both international and national organizations to decrease major pollutant emissions, urban air quality continues to worsen, affecting residential environments and harming the health of citizens [5].

Information communication technology (ICT) has contributed to addressing the challenges of improving urban air quality. Sensor networks provide a powerful tool for monitoring air quality in real-time through widely dispersed monitoring stations [6,7]. Portable air pollution sensors, combined with the global positioning system (GPS) technology, supplement an existing sensor network with enhanced availability and accessibility for monitoring air quality in near real-time $[8,9]$. Air quality information systems are available for public use in many countries [10-12]. With the proliferation of wireless communication and mobile computing technologies, mobile devices such as smart phones and tablets enable citizens to easily obtain air quality information services without 
spatial or temporal limitations [13-15]. However, as public awareness of urban atmospheric problems has risen, air pollution has now become both an environmental and social problem. Citizens are now encouraged to participate in air quality assessment and environmental governance [16,17].

Societal and technical changes require a new paradigm to develop an air quality information system and their services. Different from conventional air quality information systems, citizens are no longer only consumers of air quality information, but rather producers of air quality information. A portable air pollution sensor together with a smart phone has increased the feasibility of participatory air quality monitoring [18-20]. A large network of volunteers can measure and share personal exposures to air pollutants in regions of their interest such as a residential area nearby factories or a traffic congestion zone. Also, with mobile applications on smart phones, citizens are able to rate or report their perceptions about air qualities [21,22]. In addition, social media technology platforms are now regarded as social sensors, collecting citizens' perceptions of air quality and air pollution events [23-25]. For example, a social media service such as a blog, Twitter, and Facebook are now major communication channels for expressing the concerns of citizens about urban air quality issues. To sustainably support citizens' contribution and participation in societal environmental decision, the air quality information system needs to efficiently maintain and integrate air quality data from various sensing systems, and also to allow for citizens to easily provide and obtain air quality information services. A standardized manner is required to develop an air quality information system in that citizens can access and share air quality information in a convenient and interoperable way.

Thus, in this research, an air quality information system, which is highly coupled to GIS, was developed for the Ubiquitous Public Access to Geographic Information (UPA-to-GI) in ISO 19154 [26]. The UPA-to-GI is a geographic information service for the general public to easily access and produce geographic data or information in a ubiquitous computing environment. In the system, the UPA context information model is applied to systematically associate air quality data from various information sources including physical sensor measurements, subjective citizens' opinions, and semantic social media data. The geographic contextual relationships between users and air quality information are then characterized to provide air quality information, meeting citizens' needs. ISO 19154 is a relatively new international standard established in 2014. There have not been any cases to practically realize the UPA-to-GI environments in any domains. Therefore, another purpose in this research is to practically apply the conceptual reference model of UPA-to-GI for air quality information services.

The remainder of this paper is structured as follow. In Section 2, the UPA-to-GI defined in ISO 19154 is briefly explained to provide background information. Section 3 presents the design requirements to realize the UPA-to-GI environment for air quality information, and also illustrates how the UPA context information model is designed for air quality information services. In Section 4, a proof of concept (POC) study was conducted in Seoul, Republic of Korea. The GIS-based air quality information is implemented for citizens to access air quality information regardless of their locations and devices in use. Also, with these applications, citizens can provide their concerns about air quality at their current regions. Finally, in Section 5, this research concludes with suggestions for future studies.

\section{UPA-to-GI in ISO 19154}

\subsection{Ubiquitous Public Access to Geographic Information}

ISO/TC 211 Geographic information/Geomatics, which is a technical committee within ISO for standardization in the field of digital geographic information [27], recently presented ISO 19154 "Geographic information - Ubiquitous public access - Reference model" in 2014 [26]. The UPA-to-GI environment aims to enable the general user to have easy and seamless access to geographic data and services regardless of their locations and computing devices. Also, the user is no longer just a recipient of geographic information, but also a producer of geographic information. To realize the UPA-to-GI environment, the UPA context information model is conceptually specified to support methods to 
extract geographic context information from varied information sources including the general user. Also, within the interactions between each user and an information system, the context information model is used to characterize a user's situation in relation with geographic information. Thus, the user can access information meeting their contextual needs.

\subsection{UPA Context Information Model}

The UPA context information model is based upon seamless mobility and geographic context, which are the entity's contexts in relation to geographic information, including location, speed, and orientation, and other relevant static location data such as nearby restaurants and hospitals or dynamic data such as traffic and weather conditions. The geographic context enables an information system to provide a set of tailored geographic information artefacts, satisfying an entity's contextual requirements. However, as geographic information can be represented in various forms, the UPA context information model defines three different context levels of geographic information (Figure 1). These are: UPA locational context information model, UPA geospatial context information model, and UPA geosemantic context information model.

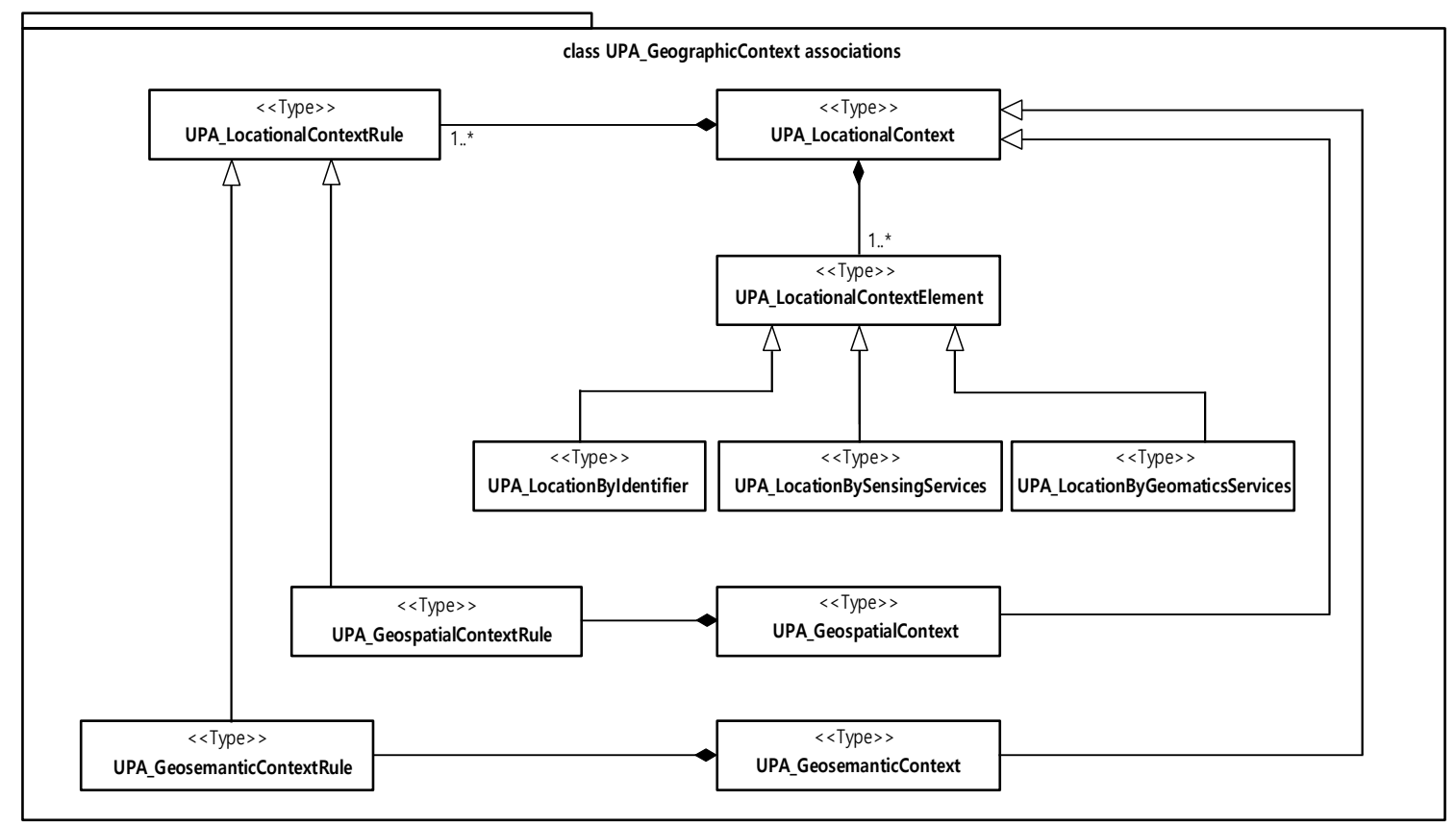

Figure 1. Geographic context information model in ISO19154 adapted from [26].

The UPA locational context information model identifies types of location that are representative of an entity (e.g., vehicle's geographic coordinate measure from GPS) and defines rules for extracting relevant contexts from the location information of the entity (e.g., vehicle's speed and orientation). In the UPA geospatial context information model, the locational entity is allocated the geospatial representation type inferred by its locational contexts (e.g., a vehicle represented as a point feature on a roadway map). The geospatial rule is used to retrieve relevant contexts from the entity's geospatial information (e.g., shortest route and travel distance computed along with a roadway map). The geosemantic context information model, which is inherited from the location context information model, employs the geospatial entity to explicitly represent the implicit expression of the locational context of the entity. The geosemantic type and set of rules are used for geographical extraction and inference of the relevant context from the locational contexts of the entity (e.g., a location of vehicle's accident inferred from a news). 


\section{Air Quality Context Information Model for UPA-to-GI}

\subsection{Overview}

The air quality information system is developed for citizens to easily access air quality in real-time, and to contribute to air quality monitoring data for participation in societal environmental decision making. To realize the UPA-to-GI for air quality information, three fundamental components in UPA-to-GI architecture for air quality information are identified in Section 3.2 They are the air quality observation system, air quality information platform, and end users (Figure 2). Also, the functional requirements to develop air quality information services are defined (Table 1) [21]. The air quality context information model refers to the UPA context information model from ISO 19154 in Figure 1. Like the UPA context information model, three different geographic context levels of air quality information are designed in Section 3.3. They are locational, geospatial, and geosemantic air quality context information models (Figure 3)

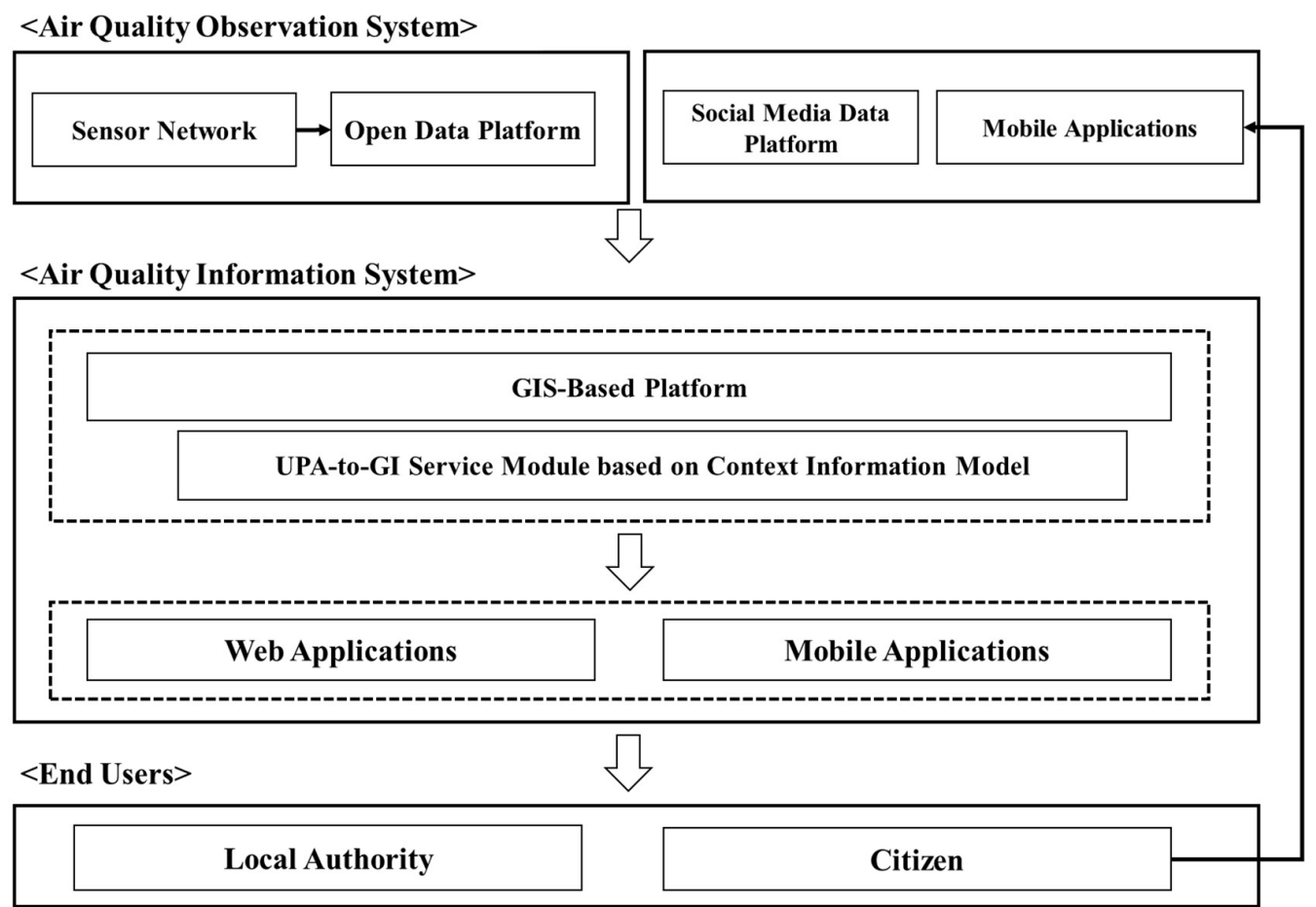

Figure 2. Conceptual framework of air quality information system for UPA-to-GI.

Table 1. List of functions to generate air quality information services from AQMA.

\begin{tabular}{|c|c|c|}
\hline User & Function & Description \\
\hline Citizen & $\begin{array}{l}\text { Registration of user } \\
\text { information }\end{array}$ & $\begin{array}{l}\text { Input user's information such as age, health status, } \\
\text { and regions of interest. Users are then categorized as general } \\
\text { and sensitive groups. }\end{array}$ \\
\hline $\begin{array}{l}\text { Citizen and } \\
\text { local authority }\end{array}$ & $\begin{array}{l}\text { Input and display of } \\
\text { citizen's opinion }\end{array}$ & $\begin{array}{l}\text { Inputs and displays citizens' perception of air quality in their } \\
\text { current regions. }\end{array}$ \\
\hline $\begin{array}{l}\text { Citizen and } \\
\text { local authority }\end{array}$ & $\begin{array}{l}\text { Display of regional air } \\
\text { quality statistics }\end{array}$ & Retrieves air quality statistics in regions of interest \\
\hline Citizen & $\begin{array}{l}\text { Display of regional air } \\
\text { quality information }\end{array}$ & Retrieves an air quality information in regions of interest \\
\hline Citizen & $\begin{array}{l}\text { Display of regional air } \\
\text { quality forecast }\end{array}$ & Retrieves an air quality forecast in regions of interest \\
\hline Citizen & $\begin{array}{l}\text { Display of location-based } \\
\text { air quality information }\end{array}$ & Retrieves air quality information at a user's current location \\
\hline
\end{tabular}




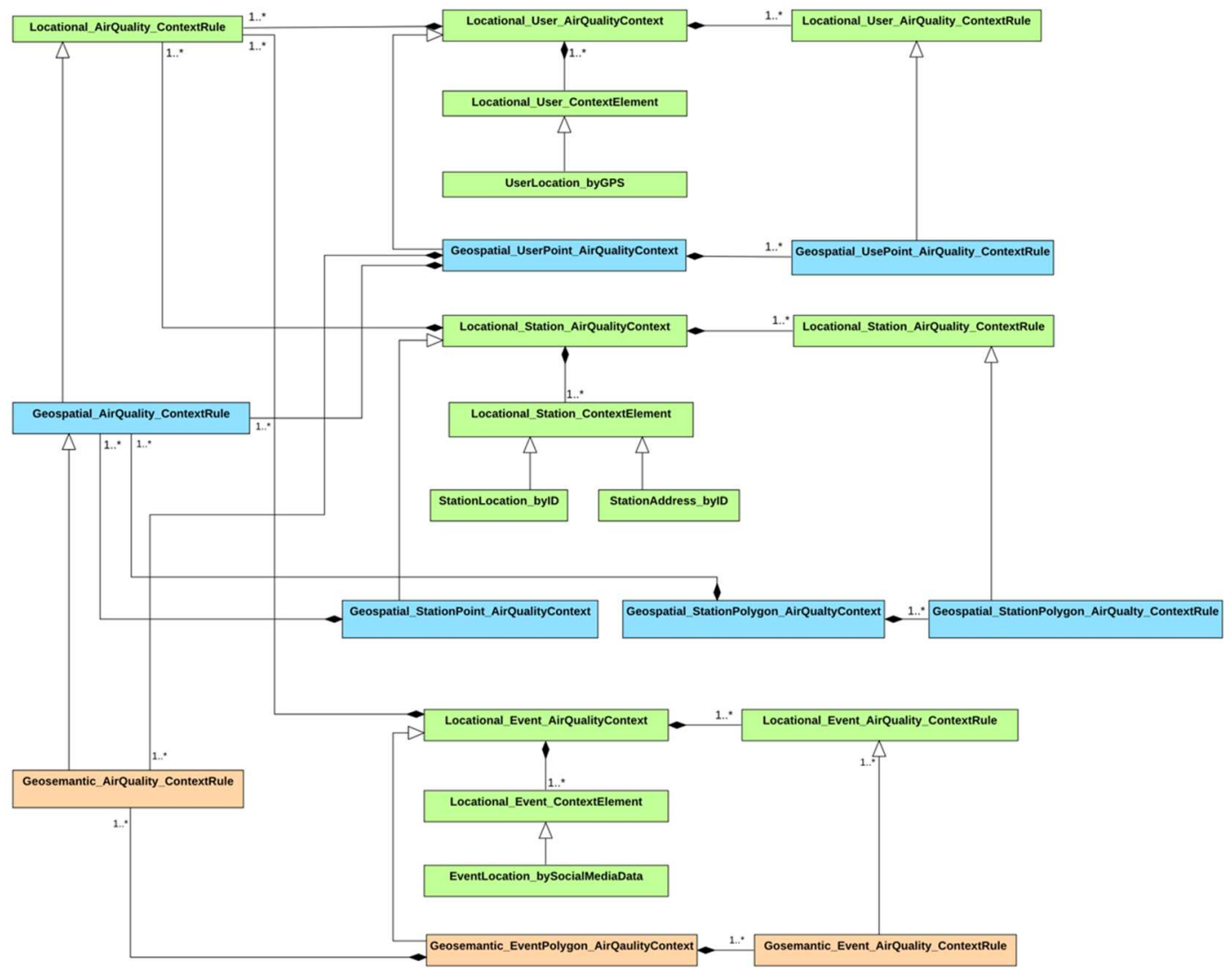

Figure 3. Air Quality Context Information Model.

\subsection{UPA-to-GI Environments for Air Quality Information}

The application of ubiquitous computing technology has led to the creation of new environments for resolving global air quality challenges. Figure 2 illustrates the conceptual framework to clarify how a ubiquitous computing technology and a GIS-based information system are interconnected to generate air quality information services from varied air quality observation systems. The air quality monitoring stations, connected in sensor networks, directly monitor air pollutants $\left(\mathrm{PM}, \mathrm{O}_{3}, \mathrm{NO}_{2}\right.$, $\mathrm{CO}$ and $\mathrm{SO}_{2}$ ) and obtain real-time data from widely dispersed locations. The sensor networks enable the Air Quality Open Data Platform (AQODP) to store and check the quality of the data obtained from the monitoring stations. The Air Quality Social Media Data Platform (AQSDP) is another channel to detect air pollution events occurring in real-time and reported within social media. The social media data, which social media users share with the public, describe any events or news that influence urban air quality such as a factory explosion. Furthermore, as public awareness of urban environmental problems has increased, Air Quality Mobile Application (AQMA) running on mobile devices can provide a mechanism for citizens to express their concerns about local air quality issues.

In ubiquitous computing environments, the air quality information platform is a bridge between heterogeneous air quality observation systems and end users. Air quality data from the observation systems are transmitted to the data hub of the platform, where the context information model employs geographic information to define how air quality data are structured and maintained. At the same time, the air quality information is explicitly or implicitly associated with users' contexts. The air quality information services are then created according to the users' location, time, and health status. The air quality platform is a basis for developing both web and mobile applications that enable users to easily access air quality information services irrespective of their locations or devices. These applications also allow users to produce air quality data based on their perceptions and opinions, which are submitted to the air quality information platform, as contributed social data. 
The main users of the air quality information services are citizens or local authorities. As shown from the functional requirements to generate air quality information services in Table 1, the context information is required for all citizens to register their age, health status, geographical regions of interest, and current location. The user is then categorized as part of the general group or sensitive group based upon analysis of their context information. Local authorities will use the air quality information services for policy or operational decision making. The air quality observation system includes the AQODP and AQSDP. Additionally, AQMA delivers a citizens' perceptions of air quality relevant to their current location, and can present their concerns about the air quality using a categorized icon. An urban map is then employed to spatially represent the perceptual concerns registered by the citizens regarding local air quality issues. Local authorities can use the knowledge and perceptive experience submitted directly from the citizens when establishing new air quality policies.

The AQMA provides estimated air quality information for a user's current location when the GPS on a mobile device is activated. Also, regional air quality and air quality forecast can be retrieved when users register a geographical region of interest. The warning message and action tip are issued when an air quality exceeds the level of health concern or when a user's location is near an air quality event. The action tip is a behavioral guideline to propose what actions the citizens should take to protect their health against each air pollutant incident. The air quality statistics, which involve current and past air quality data from AQODP, computes daily, monthly, and yearly averages for each region of a city. Citizens can refer to these statistics when deciding on where to relocate or reside for long-term health recovery purposes, whereas policy makers can use such data to judge the effectiveness of the existing air quality policies.

\subsection{Air Quality Context Information Model}

The air quality context information model primarily involves air quality data from the air quality observation systems that consists of the AQODP, AQSDP, and AQMA. In particular, AQMA running on a smart phone is utilized for users to access air quality information as well as to provide their perceptions of air quality as social data. The air quality context information model is further categorized as the locational, geospatial, and geosemantic air quality context information models that are represented as green, blue, and orange boxes, respectively in Figure 3. Each context information model is fully explained in following sections.

\subsubsection{Locational Air Quality Context Information Model}

The air quality context classes are designed for the users who use AQMA, the air quality monitoring stations that provide air quality data to AQODP, and the air pollution event detected from AQSDP. These classes are associated to retrieve and infer locational contexts from users, air quality monitoring stations, and air quality events (Table 2). The locational context classes for AQMA indicate that all users are required to register information such as their age and health status, along with specific regions of interest. Based on the registered information, the users are categorized as belonging to the general group or a sensitive group (e.g., the young, elderly, and those with respiratory/cardiovascular issues), based on their age and health status. The GPS on a mobile device provides a means to identify users' locations.

The relevant locational and air quality contexts of an air quality monitoring station can be retrieved from AQODP. A unique identity (ID) assigned to each air quality monitoring station is fundamental to collecting locational information (geographic coordinates and address), real-time air quality data $\left(\mathrm{PM}, \mathrm{CO}, \mathrm{O}_{3}, \mathrm{NO}_{2}\right.$, and $\mathrm{SO}_{2}$ ), and air quality forecasts. In addition, the air quality statistics allow comprehensive analyses of air qualities at the air quality monitoring station. In the locational context classes for AQSDP in Table 2, social media data is used to contain implicit information regarding air quality events (e.g., a forest wildfire on South Mountain, Seoul). Thus, the air pollutants (e.g., PM, $\mathrm{CO}, \mathrm{O}_{3}, \mathrm{NO}_{2}$, and $\mathrm{SO}_{2}$ ), which vary in response to air quality events, are then inferred. For example, a forest wildfire can be a source of increased PM and CO pollution around the event location. Also for 
the locational context classes for all entities in Table 2, the locational air quality context is inferred by associating locational air quality contexts from users, air quality monitoring stations, and air quality events. The inference rule identifies the air quality monitoring station within the user's region of interest, subsequently retrieving real-time (or forecasted) air quality information for that region.

Table 2. Locational air quality context class.

\begin{tabular}{|c|c|c|}
\hline Entity & Class name & General description \\
\hline \multirow{4}{*}{ AQMA } & Locational_User_AirQualityContext & $\begin{array}{l}\text { Defines user contexts according to age, health status and region } \\
\text { of interest. }\end{array}$ \\
\hline & Locational_User_AirQuality_ContextRule & $\begin{array}{l}\text { Determines a user type (general or sensitive group) according to } \\
\text { the user's information. }\end{array}$ \\
\hline & Locational_User_ContextElement, & Defines a way of retrieving a user's location. \\
\hline & UserLocation_byGPS & $\begin{array}{l}\text { Contains the 2D geographic coordinates of the user's current } \\
\text { location from GPS on a mobile device. }\end{array}$ \\
\hline \multirow{5}{*}{ AQODP } & Locational_Station_AirQualityContext & $\begin{array}{l}\text { Defines contexts of an air quality monitoring station with ID, } \\
\text { station name, past and real-time air quality data (PM, } \mathrm{CO}, \mathrm{O}_{3} \text {, } \\
\mathrm{NO}_{2} \text {, and } \mathrm{SO}_{2} \text { ), and air quality forecasts. }\end{array}$ \\
\hline & Locational_Station_AirQuality_ContextRule & Computes the air quality statistics. \\
\hline & Locational_Station_ContextElement, & Defines a way of retrieving a station's location. \\
\hline & StationLocation_byID & $\begin{array}{l}\text { Contains the geographic coordinates of the air quality } \\
\text { monitoring station. The station ID is used to retrieve its } \\
\text { geographic coordinates from AQODP. }\end{array}$ \\
\hline & StationAddress_byID & $\begin{array}{l}\text { Contains the address of the air quality monitoring station. } \\
\text { The station ID is used to retrieve its address from AQODP. }\end{array}$ \\
\hline \multirow{4}{*}{ AQSDP } & Locational_Event_AirQualityContext & $\begin{array}{l}\text { Utilizes AQSDP to define the contexts of an air pollution event } \\
\text { (e.g., ID, date and time, and the location and type of air } \\
\text { quality event). }\end{array}$ \\
\hline & Locational_Event_AirQuality_ContextRule & $\begin{array}{l}\text { Infers which air pollutants might be influenced, based on the } \\
\text { type of air quality event. }\end{array}$ \\
\hline & Locational_Event_ContextElement & $\begin{array}{l}\text { Defines a way of retrieving the air pollution event location from } \\
\text { the social media data. }\end{array}$ \\
\hline & EventLocation_bySocialMediaData & $\begin{array}{l}\text { Contains an implicit expression of the air pollution } \\
\text { event location. }\end{array}$ \\
\hline $\begin{array}{l}\text { All } \\
\text { Entities }\end{array}$ & Locational_AirQuality_ContextRule & $\begin{array}{l}\text { Associates contexts from user, air quality monitoring station, } \\
\text { and air pollution event, and infers comprehensive air quality } \\
\text { contexts (e.g., air quality information and statistics from the } \\
\text { user's region of interest). }\end{array}$ \\
\hline
\end{tabular}

\subsubsection{Geospatial Air Quality Context Information Model}

The geospatial air quality context information model refers to the geospatial context classes for a user and an air quality monitoring station. These are associated to retrieve and infer geospatial contexts from the user and the air quality monitoring station (Table 3). In the geospatial context classes for AQMA, a user's geospatial context is represented as a point feature in the air quality information system. The user's current address is determined using appropriate geocoding methods, enabling a user to rate the air quality at their current location. The rating submitted by the user is reformatted and added to the air quality information system to subjectively represent how the user feels about the air qualities in comparison with the air quality data from the monitoring station.

The geospatial context classes for AQODP indicate that the air quality monitoring stations are represented as point and polygon features in the air quality information system. In this research, an air quality monitoring station is installed in each region of the city. As air quality data from each station are representative of each region, the air quality data are coded to a polygon feature that depicts the administrative boundary of the region. As shown in the geospatial air quality contexts for the user 
and the air quality monitoring station, the air quality conditions at the user's current location can be established via geospatial operations such as inverse distance weighting (IDW) and kriging methods.

Table 3. Geospatial air quality context class.

\begin{tabular}{|c|c|c|}
\hline Entity & Class name & General description \\
\hline AQMA & Geospatial_UserPoint_AirQuality_ContextRule & $\begin{array}{l}\text { Defines a rule for inferring geospatial air quality contexts. } \\
\text { The rule defines the geocoding method to obtain a user's } \\
\text { address at the current location, and the buffering method to } \\
\text { retrieve the locations of nearby hospitals. }\end{array}$ \\
\hline \multirow[b]{2}{*}{ AQODP } & Geospatial_StationPoint_AirQualityContext & $\begin{array}{l}\text { Represents the air quality monitoring station as a point } \\
\text { feature, as inferred from the locational air quality contexts } \\
\text { for the air quality monitoring station. }\end{array}$ \\
\hline & Geospatial_StationPolygon_AirQualityContext & $\begin{array}{l}\text { Represents the air quality monitoring station as a polygon } \\
\text { feature, as inferred from the locational air quality contexts } \\
\text { for the air quality monitoring station. }\end{array}$ \\
\hline $\begin{array}{l}\text { AQMA } \\
\text { and } \\
\text { AQODP }\end{array}$ & Geospatial_AirQuality_ContextRule & $\begin{array}{l}\text { Defines a rule for inferring geospatial air quality contexts } \\
\text { from a user's location and nearby air quality monitoring } \\
\text { stations. Geospatial and interpolation operations are used to } \\
\text { infer the air quality data at the user's current location. }\end{array}$ \\
\hline
\end{tabular}

\subsubsection{Geosemantic Air Quality Context Information Model}

The geosemantic air quality context information model describes the geosemantic context classes of an air pollution event detected from AQSDP (Table 4). The geosemantic air quality contexts are inferred by retrieving and associating the geosemantic contexts of the air pollution event with a user's geospatial context. Within the air quality information system, the location of the air pollution event, which is implicitly expressed in the social media data, is explicitly represented as a polygon feature. For example, if an air pollution event implicitly refers to a fire event in a regional land mark, a buffer feature around the land mark would be created to indicate the possible location of the fire event. Also, the buffer feature represents the area of a source of air pollution (potentially generating PM and $\mathrm{CO}$, etc.). Meanwhile, the zone affected by the air pollution is determined via the types of air pollutants inferred from the air quality event. The geosemantic air qualities are inferred by retrieving and associating the geosemantic contexts of an air pollution event with a user's geospatial contexts. The geospatial operation is employed to retrieve and issue warning messages to users within the zone affected by an air quality event.

Table 4. Geosemantic air quality context class.

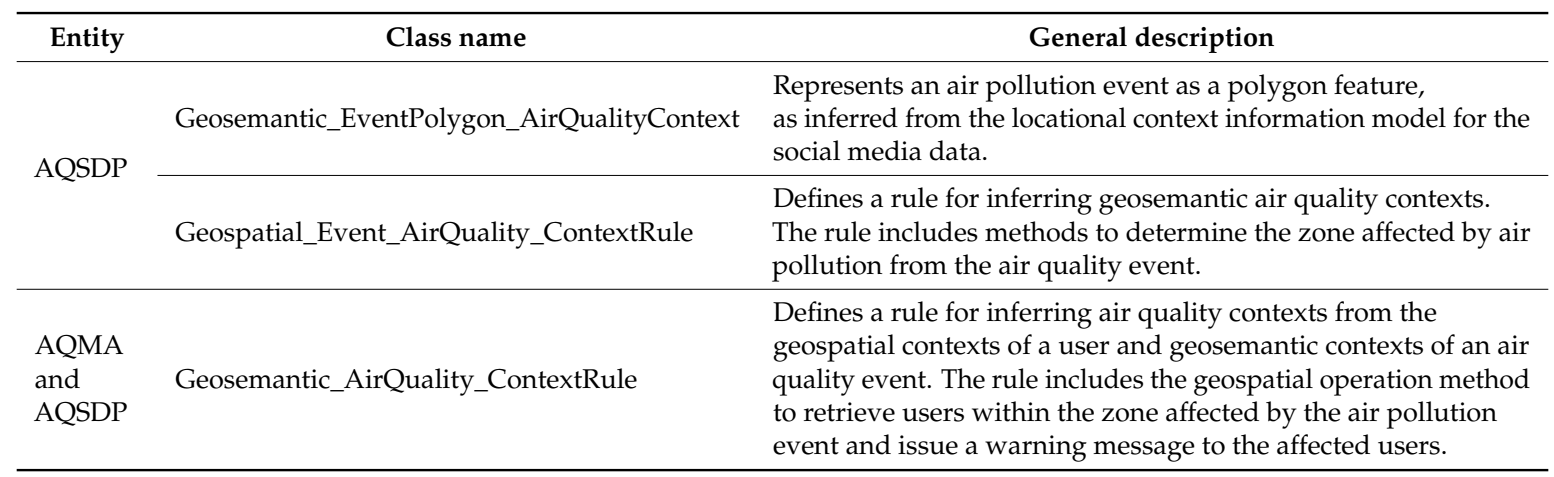




\section{Implementation and Results}

\subsection{Overview}

In this research, the air quality information system is developed based upon GIS. Also, Seoul in the republic of Korea is selected as the POC to verify the air quality information services using the air quality context information model (Figure 4). In Seoul, air quality data measured from 25 monitoring stations are transferred and stored in AQODP. More than 10 million citizens have increased concerns about the air quality problems. In the following sections, the air quality information system and its services are described.

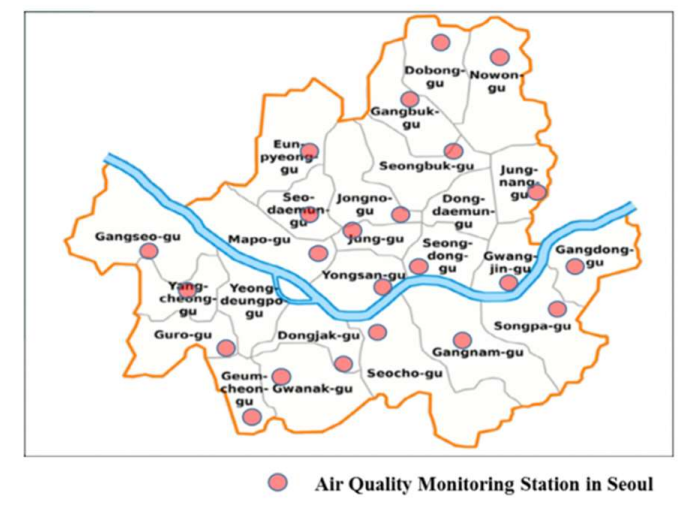

\begin{tabular}{c|c}
\hline Item & Description \\
\hline Area & $605.25 \mathrm{~km}^{2}$ \\
\hline Number of Districts & 25 \\
\hline Population & $10,581,728$ \\
\hline Population Density & $17,000 / \mathrm{km}^{2}$ \\
\hline
\end{tabular}

Figure 4. POC Site: Seoul, Republic of Korea.

\subsection{Air Quality Information System}

The air quality information system in Figure 5 was developed using open source software technology, and consists of three main components: a database, a server, and a client interface. The database system is built using PostgreSQL and the Post-GIS geospatial data plug-in for PostgreSQL is used to save, retrieve, and analyze air quality data. The server, which was constructed based on Apache/Tomcat configuration, uses both Socket module and HTTP client module to collect air quality data from external platforms such as AQODP and AQSDP. In the system, air quality data are associated with geographic information. The GeoServer platform is employed to activate both a WMS (Web Map Service) and WFS (Web Feature Service). In addition, the Restlet framework is used to provide the air quality information smoothly for web/mobile client devices. To render the geographical representations of air quality information, the mobile clients use Leaflet libraries. In this research, the mobile client, which was developed on Google Android, provides a robust platform to deploy the UPA-to-GI based air quality information service.

The air quality information system collects air quality data from the air quality observation systems, in which the air quality contexts are than extracted and associated with contexts from users to provide relevant air quality information services. The air pollutants measured from the air quality monitoring station are simply numerical data; therefore, they are converted into a region-appropriate Air Quality Index (AQI) scheme to help citizens more easily understand air quality levels and to protect their health during episodes of severe air pollution. AQI indicates overall air quality derived from all air pollutant measurements. Also, the health implications corresponding to index categories are shown in Table 5. Different countries employ specific air quality indices, corresponding to their respective national air quality standards. This technical report presents examples using the Comprehensive Air Quality Index (CAI) and behavioral guidelines established for use in the Republic of Korea [28]. 


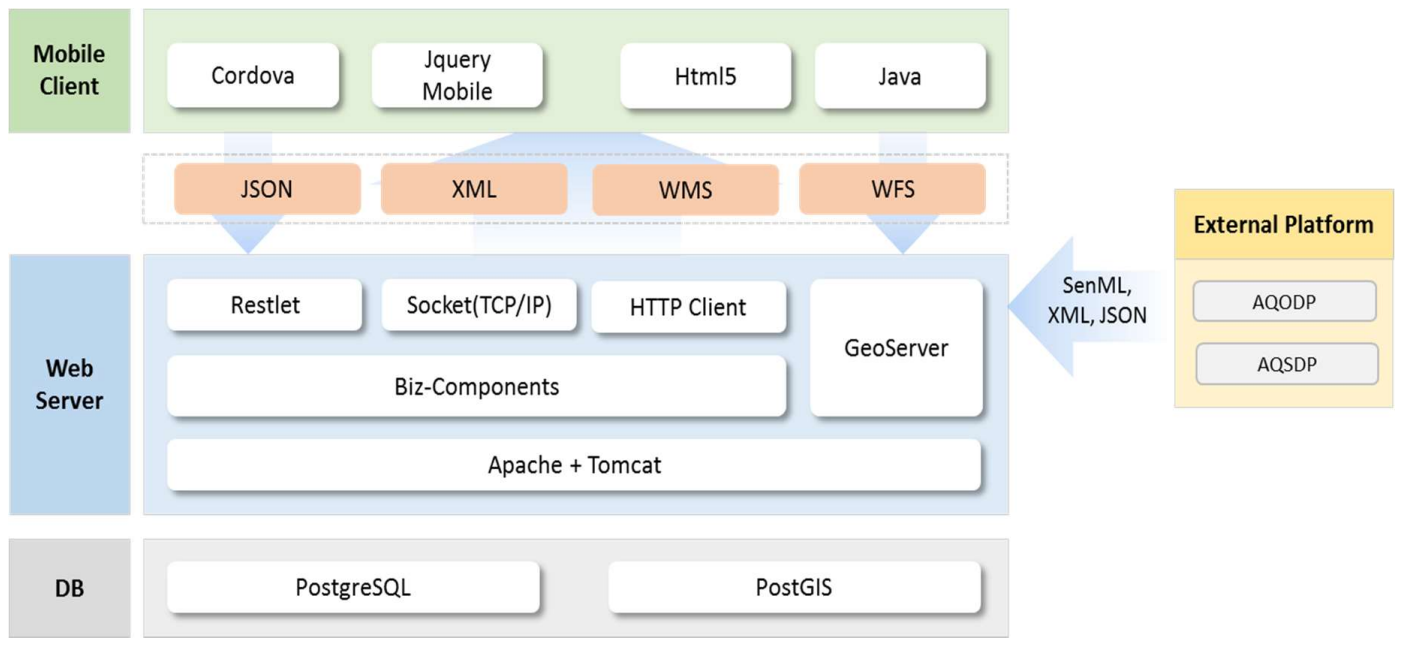

Figure 5. Overall architecture of air quality information system.

Table 5. Air quality index and its health implication.

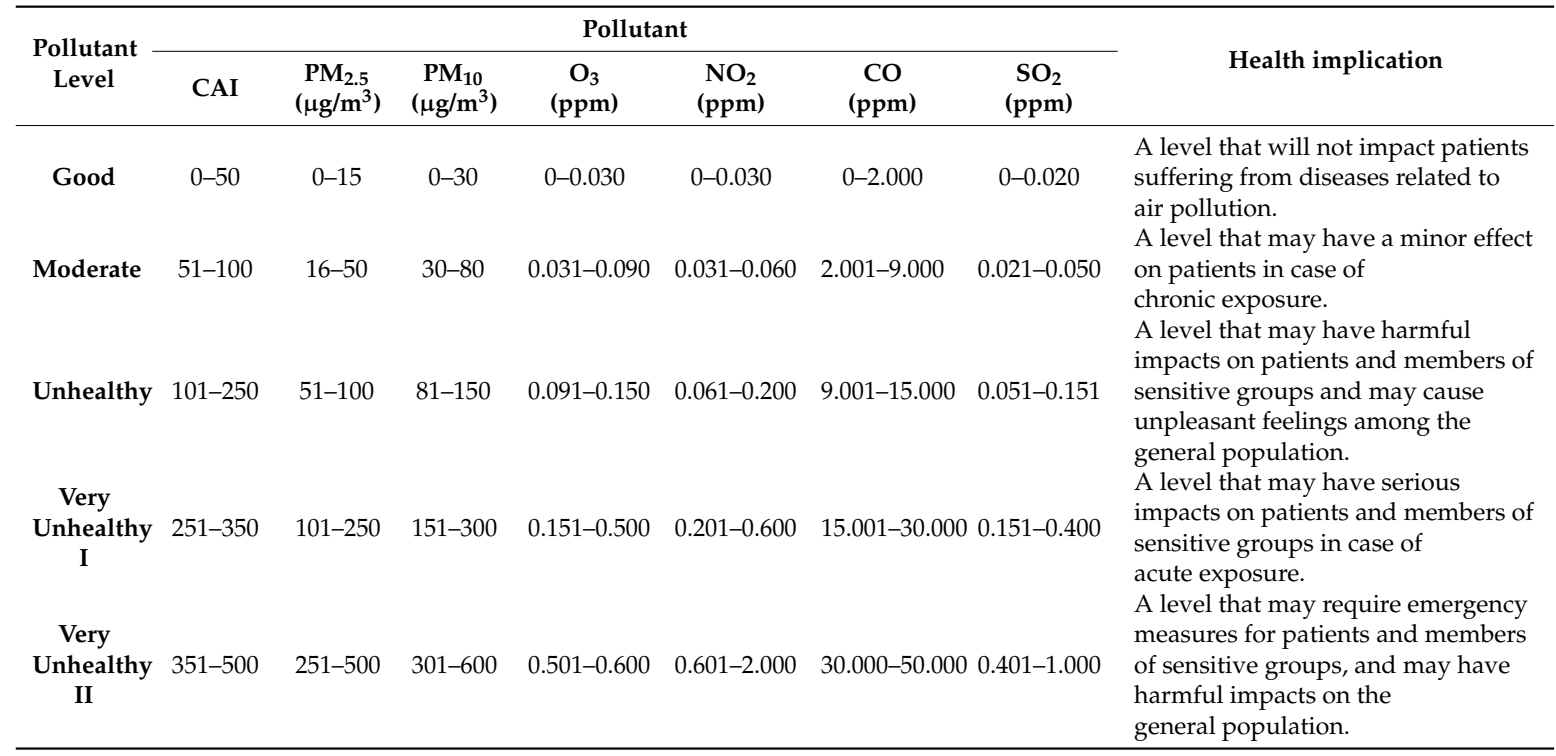

\subsection{Air Quality Information Service}

The air quality information service is developed according to the air quality context information model described in Section 4, and thus it consists of locational, geospatial, and geosemantic air quality information services. The locational air quality information service is formulated based upon extracted or inferred locational contexts from the user and the air quality monitoring station. Figure 6 shows interface applications for locational air quality information services such as a real-time air quality information for regions of interest, air quality statistics, and an air quality forecast. The locational air quality information service is a function of associating locational air quality contexts from users and air quality monitoring stations. The user's locational contexts, which are registered in AQMA, include multiple regions of interest. The locational contexts of an air quality monitoring station can be retrieved from AQODP. The unique ID, assigned for each air quality monitoring station, is used as a key to retrieve its address and to collect real-time air quality information and air quality forecasts. The real-time (or forecasted) air quality information can be retrieved in accordance with a user's region of interest (Figure $6 \mathrm{a}, \mathrm{b}$ ). In addition, the air quality statistics provide a comprehensive view to spatially and temporally analyze the air quality at the location of the air quality monitoring station (Figure 6c). 


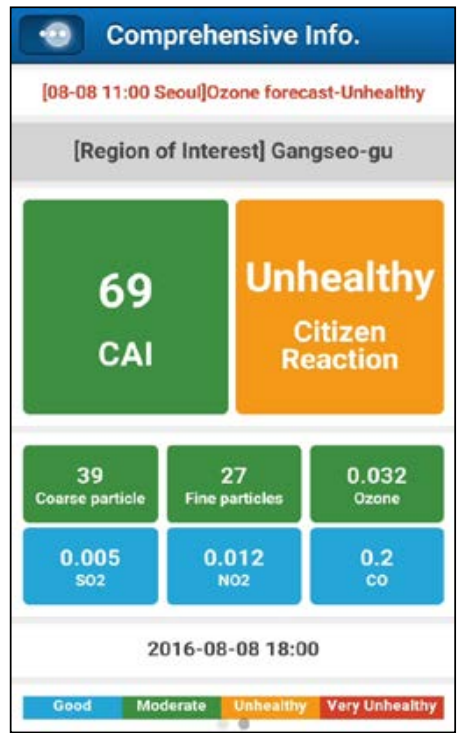

(a)

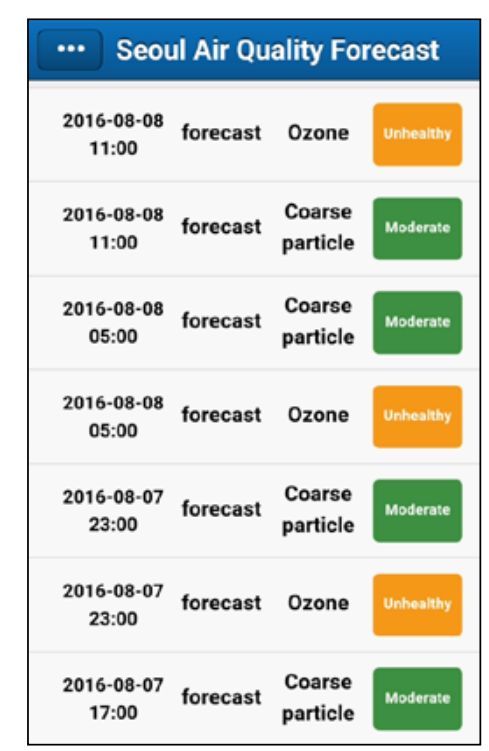

(b)

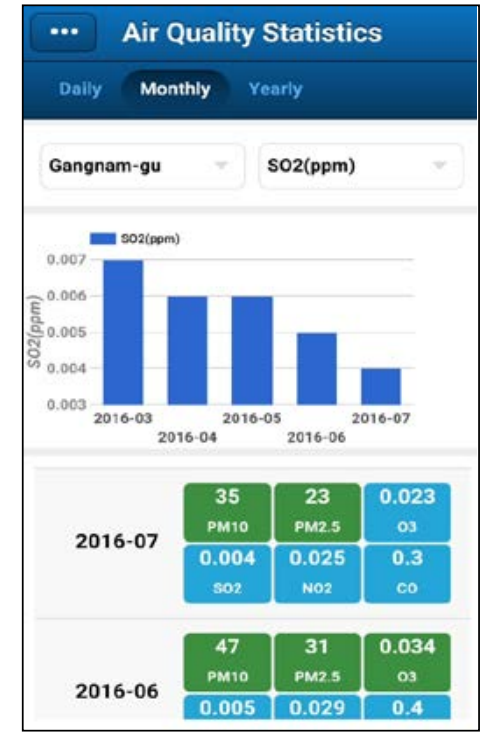

(c)

Figure 6. Sample examples of locational air quality information service. (a) Comprehensive air quality information in region of interest; (b) air quality forecast; (c) Air quality statistics $\left(\mathrm{SO}_{2}\right.$ in Gangnam-gu, Seoul).

In the air quality information system, the geospatial air quality information is generally shown in conjunction with an urban map. The position of the user is encoded as a two-dimensional geographic coordinate pair, which is obtained from GPS on the mobile device, and represented on the map using a point symbol. Figures 7 and 8 show examples of the geospatial air quality information service. In Figure 7a, the geospatial context of the air quality monitoring station is represented with polygon feature. An air quality monitoring station is installed in each region of the city. As air quality data from each station is representative for each region, the air quality data is associated with the polygon feature that depicts a specific administrative area of the region. In Figure $7 \mathrm{~b}$, the air quality values at the user's current location are interpolated with the IDW method. The air quality estimate can be varied depending on the choice of interpolation methods such as IDW, kriging, spatial averaging, and nearest neighbor [29-31]. Although the kriging method is generally known to produce the most reliable air quality estimate between monitoring stations, the IDW method is selected considering the computational complexity and efficiency to deliver air quality information in real-time. In Figure 7c, the geocoding method is used to obtain a user's address at the current location, and the buffering method to retrieve the locations of nearby hospitals. In addition to the users' contexts registered in AQMA, the hospital distribution also becomes the users' contexts. Hospital information is necessary when users with respiratory or cardiovascular issues need immediate medical treatments. Figure 8a shows the air quality questionnaire to rate the perception of air quality. The user's current address, which is computed using the geocoding method, enables the users to express their perception of air quality at their current regions (Figure 8b). The user's rating is used as social data to subjectively represent how they feel about the air quality at their current region in comparison to the air quality data from the monitoring station. 


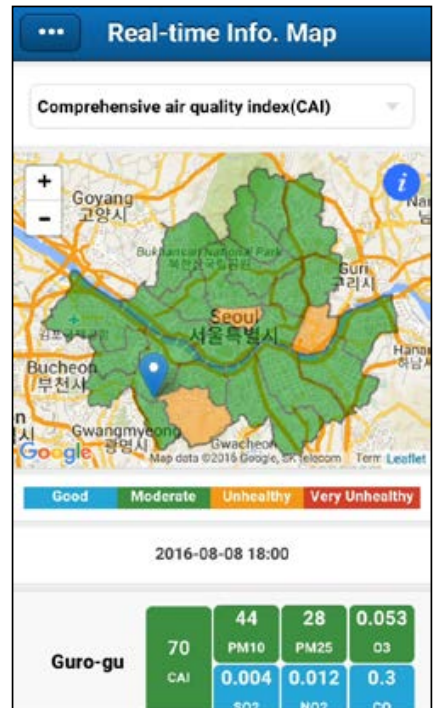

(a)

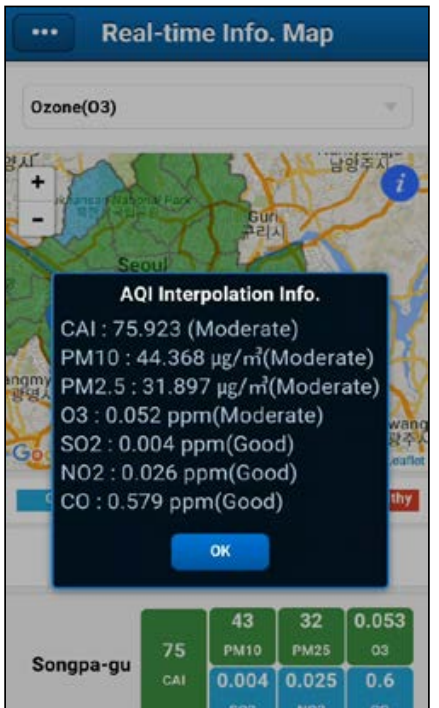

(b)

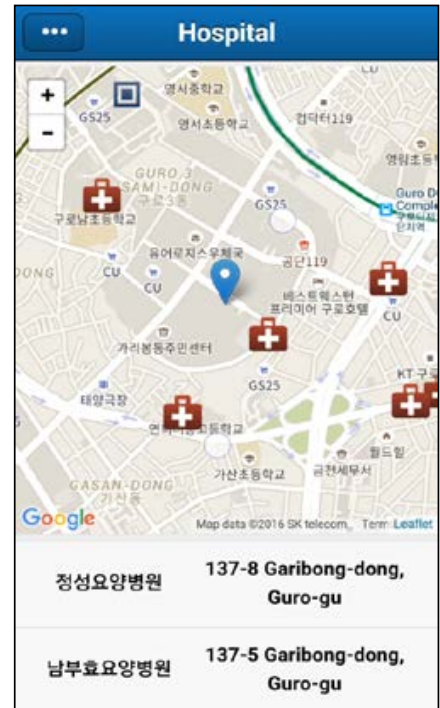

(c)

Figure 7. Sample examples of geospatial air quality information service. (a) Regional air quality information; (b) location-based air quality information; (c) citizens' perception map of air quality.

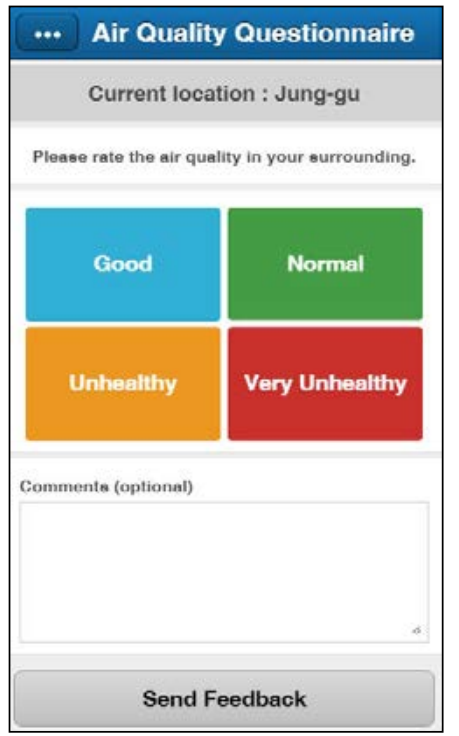

(a)

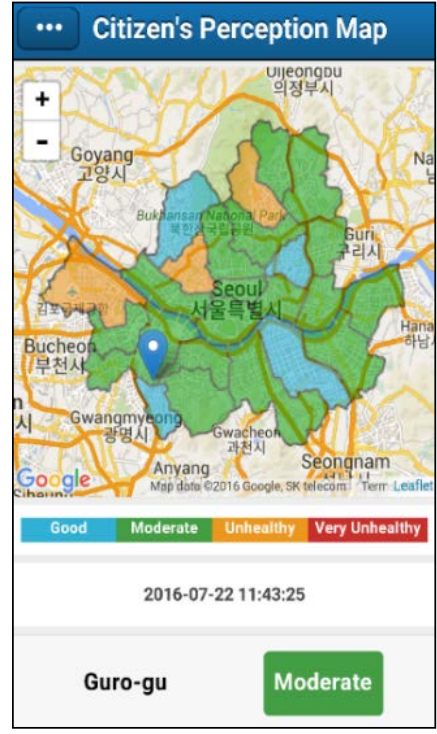

(b)

Figure 8. Sample examples of geospatial air quality information service. (a) Air quality questionnaire; (b) citizen's air quality perception map.

The geosemantic air quality information service includes the air pollution event map and the warning message. The social media data, which is transmitted from AQSDP, contains implicit locational information of air quality events. Thus, the air quality information system employs the geospatial entities to explicitly represent air quality events overlaid on the urban map. Air pollutants, which are potentially influenced by the air quality event, can then be inferred. In Figure 9a, the buffer indicates an area that social media data refer to as a fire in a factory. In Figure 9b, the highlighted polygon indicates that the social media data refer to a fire somewhere in Yeoui-Dong, Seoul. The warning message is then shown to users currently located near the event, indicating that individuals sensitive to air pollution 
should exercise caution, in that the factory explosion might cause all kinds of air pollution and the fire might lead to high concentrations of CO and PM.

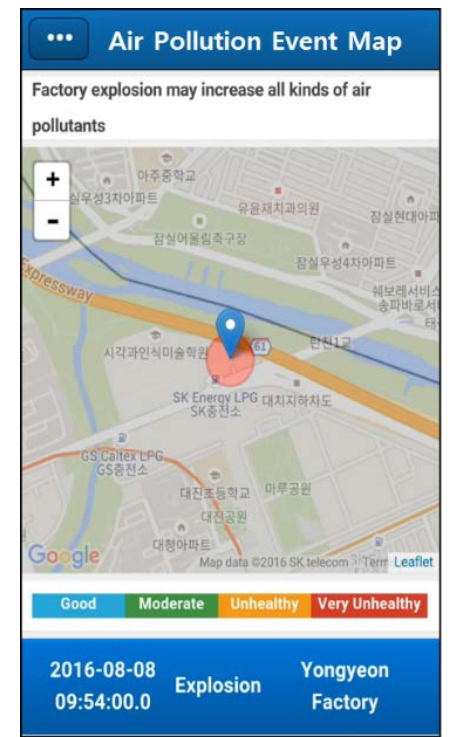

(a)

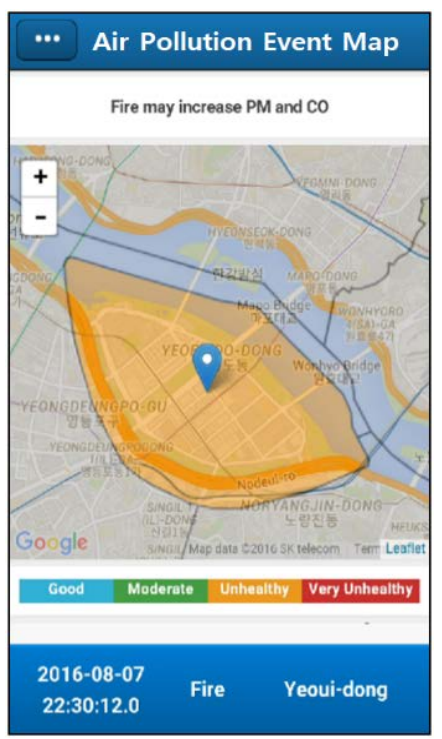

(b)

Figure 9. Sample examples of geosemantic air quality information. (a) Air pollution event map with a buffer; (b) air pollution event map with a regional polygon.

\section{Discussion and Conclusions}

Air pollution has continued to worsen, despite dedicated international and national initiatives to improve air quality. Air quality has already become one of the environmental risks to health, affecting the quality of citizens' lives. Recently, the advance in ICT has stimulated a shift of technical and societal paradigms to develop an air quality information system and its services. With the proliferation of wireless communication and mobile computing technologies, a portable device with GPS technology (e.g., a smart phone and a tablet PC) enables citizens to easily access air quality information without spatial and temporal limitations. Citizens have also become providers of air quality information. However, varied information types from heterogeneous data sources require a convenient and interoperable standard to design and develop an air quality information system and its services to end users.

In this regard, an air quality information system, based on the UPA context information model in ISO 19154, was developed. This system, which is highly coupled to GIS, provides a means of raising the environmental awareness of citizens as well as promoting their participation in civic environmental decisions. The air quality context information model implemented in the system has a central role to collect, extract, and associate contextual air quality information from heterogeneous air quality observation systems. The air quality context information model is used to characterize the contexts of users, air quality monitoring station, and air quality events in relation with geographic information. The air quality context information model is categorized as a locational, geospatial, and geosemantic context information model. Therefore, different levels of a contextual relationship between users and air quality information can be defined, from which more tailored air quality information services can be generated considering user's contextual requests. For validation and verification purposes, an air quality information system based on the air quality context information model was implemented for citizens of Seoul, South Korea. Implementation results showed that the air quality information system generated spatially relevant air quality information services, depending on the location and air quality 
situations near a specific user. The implemented system also allowed citizens to assess the air quality at their current locations or in regions of interest.

This research was only concerned with the design of the air quality context information model to realize UPA-to-GI for improving urban air qualities. However, each city has unique atmospheric and social environments. For example, a selection of an interpolation method is dependent on a density of air quality monitoring stations and a spatial structure of an urban area. Accurate estimates of air quality information requires additional information (e.g., wind direction and velocity), spatial models (e.g., 3D terrain and building models), air dispersion model, and others. Also, to supplement air quality information from a limited number of air quality monitoring stations, a citizen's involvement will be a powerful means to monitor air pollutants from hot spots (e.g., heavy traffic roadway and industrial zone). Therefore, in future studies, these theoretical and practical concerns should be made to enhance the air quality context information model so that the air quality information system will be improved to promote the civic participation, and ultimately decision makers in public authorities can utilize air quality information as a reference to establish air quality policies.

Funding: This research received no external funding.

Acknowledgments: The research article was supported by the research project "FTCR (Department of Future Technology and Convergence Research) Strategy and R\&D Capability Development Plan" funded from KICT (Korea Institute of Civil Engineering and Building Technology).

Conflicts of Interest: The author declares no conflict of interest.

\section{References}

1. Jindal, S.K. Air quality guidelines: Global update 2005. particulate matter, ozone, nitrogen dioxide and sulfur dioxide. Indian. J. Méd. Res. 2007, 126, 492-493.

2. Patel, A.; Chaudhary, H.; Patel, K.; Sen, D. Air pollutants all are chemical compounds hazardous to ecosystem. World. J. Pharm. Sci. 2014, 2, 729-744.

3. World Health Organization. Ambient Air Pollution: A Global Assessment of Exposure and Burden of Disease; World Health Organization: Geneva, Switzerland, 2016.

4. Elsom, D. Smog Alert: Managing Urban Air Quality; Routledge: London, UK, 2014.

5. Marlier, M.E.; Jina, A.S.; Kinney, P.L.; DeFries, R.S. Extreme air pollution in global megacities. Curr. Clim. Chang. Rep. 2016, 2, 15-27. [CrossRef]

6. Liu, J.H.; Chen, Y.F.; Lin, T.S.; Lai, D.W.; Wen, T.H.; Sun, C.H.; Juang, J.Y.; Jiang, J.A. In developed urban air quality monitoring system based on wireless sensor networks. In Proceedings of the Fifth International Conference on Sensing Technology (icst), Palmerston North, New Zealand, 28 November-1 December 2011; pp. 549-554.

7. Khedo, K.K.; Perseedoss, R.; Mungur, A. A wireless sensor network air pollution monitoring system. Int. J. Wirel. Mob. Netw. 2010, 2, 31-45. [CrossRef]

8. Mead, M.I.; Popoola, O.; Stewart, G.; Landshoff, P.; Calleja, M.; Hayes, M.; Baldovi, J.; McLeod, M.; Hodgson, T.; Dicks, J. The use of electrochemical sensors for monitoring urban air quality in low-cost, high-density networks. Atmos. Environ. 2013, 70, 186-203. [CrossRef]

9. Devarakonda, S.; Sevusu, P.; Liu, H.; Liu, R.; Iftode, L.; Nath, B. In real-time air quality monitoring through mobile sensing in metropolitan areas. In Proceedings of the 2nd ACM SIGKDD International Workshop on Urban Computing, Chicago, IL, USA, 11 August 2013; p. 15.

10. European Environment Agency. European Air Quality Index. Available online: https://www.eea.europa. eu/themes/air/air-quality-index/index (accessed on 22 July 2018).

11. Seoul Air Quality Information. Available online: http://english.Seoul.Go.Kr/policy-information/ environment-energy / air-quality-information/1-air-quality-information/ (accessed on 15 June 2018).

12. United States Environmental Protection Agency Airnow. Available online: https://www.airnow.gov/ (accessed on 12 March 2018).

13. 4sfera Innova. Europeair. Available online: https://play.Google.Com/store/apps/details?id=com. girosystem.europeair (accessed on 12 June 2018). 
14. BrezonMeter. Air Quality Index. Available online: https://play.Google.Com/store/apps/details?Id=app. Breezometer (accessed on 12 June 2018).

15. Weblim. Air Pollution. Available online: https://play.google.com/store/apps/details?id=com.apurav.apps. airquality (accessed on 19 July 2018).

16. Paulos, E.; Honicky, R.J.; Hooker, B. Citizen science: Enabling participatory urbanism. In Handbook of Research on Urban Informatics: The Practice and Promise of the Real-time City; IGI Global: Berkeley, CA, USA, 2009; pp. 414-436.

17. Bailey, P.; Yearley, S.; Forrester, J. Involving the public in local air pollution assessment: A citizen participation case study. Int. J. Environ. Pollut. 1999, 11, 290-303. [CrossRef]

18. Hasenfratz, D.; Saukh, O.; Sturzenegger, S.; Thiele, L. Participatory air pollution monitoring using smartphones. In Proceedings of the 2nd International Workshop on Mobile Sensing: From Smartphones and Wearables to Big Data, Beijing, China, 16-20 April 2012.

19. Predic, B.; Yan, Z.; Eberle, J.; Stojanovic, D.; Aberer, K. ExposureSense: Integrating daily activities with air quality using mobile participatory sensing. Presented at PerCom Workshops, San Diego, CA, USA, 19 March 2013; pp. 303-305.

20. Snik, F.; Rietjens, J.H.; Apituley, A.; Volten, H.; Mijling, B.; Di Noia, A.; Heikamp, S.; Heinsbroek, R.C.; Hasekamp, O.P.; Smit, J.M. Mapping atmospheric aerosols with a citizen science network of smartphone spectropolarimeters. Geophys. Res. Lett. 2014, 41, 7351-7358. [CrossRef]

21. Hong, S. Design of air quality information service based upon geographic context information model in iso19154. Spat. Inf. Res. 2017, 25, 39-47. [CrossRef]

22. Castell, N.; Fredriksen, M.; Cole-Hunter, T.; Robinson, J.; Keune, H.; Nieuwenhuijsen, M.; Bartonova, A. CityAir App: Mapping Air-quality Perception Using People as Sensors; EGU General Assembly: Vienna, Austria, 2016; p. 5649.

23. Wang, S.; Paul, M.J.; Dredze, M. Social media as a sensor of air quality and public response in china. J. Méd. Int. Res. 2015, 17, e22. [CrossRef] [PubMed]

24. Resch, B. People as sensors and collective sensing-contextual observations complementing geo-sensor network measurements. In Progress in Location-based Services; Springer: Berlin, Germany, 2013; pp. 391-406.

25. Kay, S.; Zhao, B.; Sui, D. Can social media clear the air? A case study of the air pollution problem in chinese cities. Prof. Geogr. 2015, 67, 351-363. [CrossRef]

26. International Organization for Standardization (ISO). ISO 19154:2014 Geographic information - Ubiquitous public access - Reference model. Available online: https://www.iso.org/obp/ui/\#iso:std:iso:19154:ed-1:v1: en:fn:6 (accessed on 17 July 2018).

27. ISO/TC211. Available online: https:/ / www.iso.org/committee/54904.html (accessed on 17 July 2018).

28. National Institute of Environmental Research. Improvement of comprehensive air quality index in accordance with the air quality forecast alert information; National Institute of Environmental Research: Incheon, Korea, 2014.

29. Wong, D.W.; Yuan, L.; Perlin, S.A. Comparison of spatial interpolation methods for the estimation of air quality data. J. Expo. Sci. Environ. Epidemiol. 2004, 14, 404. [CrossRef] [PubMed]

30. Son, J.Y.; Bell, M.L.; Lee, J.T. Individual exposure to air pollution and lung function in korea: Spatial analysis using multiple exposure approaches. Environ. Res. 2010, 110, 739-749. [CrossRef] [PubMed]

31. Denby, B.; Horálek, J.; Walker, S.E.; Eben, K.; Fiala, J. Interpolation and assimilation methods for european scale air quality assessment and mapping Part I: Review and Recommendations. Available online: https: / /www.researchgate.net/profile/Sam-Erik_Walker/publication/242220876_Interpolation_ and_assimilation_methods_for_European_scale_air_quality_assessment_and_mapping_Part_I_Review_ and_recommendations/links/00b7d52e9717e99029000000/Interpolation-and-assimilation-methods-forEuropean-scale-air-quality-assessment-and-mapping-Part-I-Review-and-recommendations.pdf (accessed on 17 July 2018).

(C) 2018 by the author. Licensee MDPI, Basel, Switzerland. This article is an open access article distributed under the terms and conditions of the Creative Commons Attribution (CC BY) license (http://creativecommons.org/licenses/by/4.0/). 